\title{
Chemical Investigation of Some Capparis Species Growing in Egypt and their Antioxidant Activity
}

\author{
Ahmed R. Hamed, Khaled A. Abdel-Shafeek, Nahla S. Abdel-Azim, Shams I. Ismail and \\ Faiza M. Hammouda
}

Phytochemistry Department, National Research Centre, El Bohoth Street, 12311, Dokki, Egypt

Capparis cartilaginea and $C$. deserti growing in Egypt were investigated for their glucosiolates and rutin content. From Capparis cartilaginea four isothiocynates were isolated and identified using GC and EI/MS techniques. These compounds were butyl isothiocyanate (1), 6-methylsulphonylhexyl isothiocyanate (2), 7-methylsulphonylheptyl isothiocyanate (3) and 5-benzylsulphonyl-4-pentenyl isothiocyanate (4). In addition to compounds (1) and (2), two other compounds were isolated and identified from Capparis deserti. These compounds are 3-methylthiopropyl isothiocyanate (5) and [11-(2-butenylthio)6-undecenyl isothiocyanate] (6). Compounds (1), (2), (5) and (6) are reported in this study for the first time from Capparis deserti. The main flavonoid component in the studied species was isolated and identified as rutin by comparing the data with those reported. Also, quantitative evaluation of rutin in the two species was carried out by TLC-densitometric analysis. The antioxidant activity was done using diphenylpicrylhydrazyl (DPPH) radical scavenging method. The butanol fraction from C. cartilaginea and $C$. deserti showed the highest antioxidant properties.

Keywords: antioxidant activity - Capparis cartilaginea - Capparis deserti - glucosinolates rutin - TLC-densitometry

\section{Introduction}

Family Capparaceae comprises 39 genera and 650 species distributed through warm regions (1). The genus Capparis comprises 250 species including shrubs, trees and woody climbers. This genus is represented in Egypt by six species (2). Dioscorides recommended the use of the leaves and roots of Capparis spinosa L. to reduce swelling and calm the pain of teeth (3).

In the Arabian folk medicine, several Capparis species have many uses. The total herb of Capparis cartilaginea Decne. is used for bruises, childbirth, earache, headache, paralysis, snakebite and swelling. Also the fruits of Capparis decidua (Forssk.) Edgew are used to relieve difficult breathing as a laxative, anthelimintic and for

For reprints and all correspondence: Prof. Faiza M. Hammouda, Phytochemistry Department, National Research Centre, El Bohoth Street, 12311, Dokki, Egypt. Tel: 002023371 211; Fax: 00202 3370 931; E-mail: fmhammouda@hotmail.com nervous disorders. Furthermore, the leaves of Capparis spinosa are used for treating earache, coughs, expelling stomach worms and for diabetes (4) while the bark is used for the treatment of gout, rheumatism and as a laxative and expectorant for chest diseases. The bark is also used in liver affections. Infusion of stem and root bark is used for diarrhea and febrifuge. Also the flower buds and roots are used as renal disinfectants, diuretic, tonic and for arteriosclerosis and as compresses for the eyes (5).

In 1972, Ahmed et al. investigated some Egyptian Capparis species for the presence of glucosinolates. The authors isolated glucoiberin, glucocapparin, sinigrin, glucocleomin, glucobrassicin and glucocapangulin. Also, four flavonoids were isolated from $C$. cartilaginea and C. deserti and identified as kaempferol-3-O-rutinoside, quercetin-3-O-rutinoside, quercetin-7-O-rutinoside and quercetin-3-)-glucoside-7-O-rhamnoside (6).

In this study we report the isolation and identification of isothiocynates from $C$. cartilaginea and $C$. deserti 
growing in Egypt as well as the evaluation of rutin content by TLC-densitometry analysis. Also, the antioxidant activity of different fractions of two species was studied (8).

\section{Experimental}

\section{General}

GC/MS was done using Finnigan SSQ 7000 under the following conditions: Column: DB5 capillary column, I.D. $0.25 \mathrm{~mm}$; Ionization mode: EI (70-ev); Temperature program: $50-250 \quad\left(4^{\circ} \mathrm{C} / \mathrm{min}\right)$; Detector: FID; Sample volume: $2 \mu 1$; Mass range: 50-750 mass unit UV absorbances were measured using Schimadzu UV 2401 PC UV-recording spectrophotometer; TLC-densitometry analysis was carried out using CAMAG ATS III and TLC Scanner 3 with CATS 4 software. TLC was carried out on silica gel plates (Merck $60 \mathrm{~F} 254,20 \times 20 \mathrm{~cm}$ ). One percent solutions of standard rutin and extracts were prepared. The mobile phase was: EtOAC, $\mathrm{AcOH}$, $\mathrm{HCOOH}, \mathrm{H}_{2} \mathrm{O}$ (10: 1: 1: 1). Wavelength scan at $366 \mathrm{~nm}$.

\section{Plant Material}

C. cartilaginea Decne and C. deserti Zoh. were collected from Wadi Zaghra, Dahab, South Sinai, Egypt. The plants were identified by Prof. N. El-Hadidi, Prof. of Botany, Faculty of Science, Cairo University, Egypt. The plant samples were air-dried in a good air draft in the absence of direct sunlight and then ground.

\section{Glucosinolates}

The defatted plant material was air-dried and extracted with $80 \%$ ethanol. The combined alcoholic extracts were concentrated in vacuo at $50^{\circ} \mathrm{C}$, dissolved in hot distilled water, filtered and left overnight in the refrigerator to remove any resinous material. Two-thirds of the clear aqueous filtered extract was successively partitioned with chloroform, ethylacetate and finally with butanol. Each extract was dried over anhydrous sodium sulfate (Merck, Germany) and evaporated in vacuo at $50^{\circ} \mathrm{C}$.

The remaining third of the clear aqueous filtrate was diluted with distilled water and allowed to pass slowly through a column of acidic aluminum oxide (Anionotropic, $800 \mathrm{~g}$, Sigma chemical Co., activity grade-I, type WA-I acidic). The column was washed with distilled water till the elute was colorless and then eluted with $2 \%$ aqueous potassium sulfate solution. The collected fractions were evaporated under reduced pressure at about $45^{\circ} \mathrm{C}$ till dryness. The aqueous residue was extracted with hot ethanol and filtered. The combined ethanol extract was concentrated in vacuo at $45^{\circ} \mathrm{C}$ and the residue was dissolved in distilled water and lyophilized to give a brownish residue (total glucosinolate fraction).

\section{Enzymatic Hydrolysis}

About $1 \mathrm{~g}$ of the total glucosinolates of C. cartilaginea was dissolved in $10 \mathrm{ml}$ double-distilled water. The solution was buffered with sodium citrate at $\mathrm{pH}$ 6. Five milligram of myrosinase (Sigma-Aldrich, Germany) were added and incubated at $28^{\circ} \mathrm{C}$ for $24 \mathrm{~h}$. The enzymatic hydrolysis was blocked by saturating the solution with sodium chloride. The hydrolysate solution was exhaustively partitioned with diethyl ether. The combined ether extract was washed with distilled water, dehydrated over anhydrous sodium sulfate and evaporated in vacuo at $30^{\circ} \mathrm{C}$. Semisolid yellow (isothiocyanates) residue was obtained and was subjected to GC/MS analysis. (9)

\section{Flavonoids}

Paper chromatographic investigation [Whatman No. 1, $15 \%$ acetic acid, $n$-butanol: acetic acid: water $(4: 1: 5$ and $3: 1: 1)$ ] of ethyl acetate and butanol fractions of both C. cartilaginea and $C$. deserti revealed the presence of a main component which was visualized by spraying with $1 \%$ alcoholic $\mathrm{AlCl}_{3}$ and $\mathrm{NA}$ reagent. Preparative PC (3 MM, 15\% aqueous acetic acid) followed by Sephadex $\mathrm{LH}_{20}$ column ( $90 \%$ methanol) was used for isolation and purification of the main flavonoidal compound.

\section{Thin Layer Densitometric Assay}

\section{Sample Solutions}

One percent of standard and samples stock solutions were prepared.

\section{Method}

A CAMAG automatic TLC Scanner with CATS evaluation software was used with the following settings: wavelength $520 \mathrm{~nm}$, scanning speed $20 \mathrm{~mm} \mathrm{~s}^{-1}$, multi level calibration via peak area by polynomial regression, silica gel 60 F254 $(20 \times 20 \mathrm{~cm}$, Merck) plates were used. Samples were applied band wise using CAMAG automatic TLC sampler III under the following conditions: distance from lower edge $=10 \mathrm{~mm}$, band length $=8 \mathrm{~mm}$, track distance $=12$, No. of applications $=14$.

\section{Determination of Scavenging Effect on DPPH Radicals (ref)}

The decrease of the absorbance at $516 \mathrm{~nm}$ of the DPPH solution after addition of the sample (plant materials) was 
measured in a glass cuvette. An aliquot of $0.1 \mathrm{ml} \mathrm{M}$. methanol solution of DPPH was mixed with the methanolic solution of the sample, so that the relative concentration of plant materials versus the stable radical in the cuvette was 0.14 , then the solution with tested sample was shaken vigorously. The absorbance was mentioned at the start and after 30 min. after being kept in the dark against a blank of methanol without DPPH. All tests were run in duplicate and averaged. The antioxidative of these samples were compared with Trolox where

$$
\begin{aligned}
\% \text { RSA }= & 100 \% \\
& \times \frac{\text { Abs of blank } 516 \mathrm{~nm}-\text { Abs of sample } 516 \mathrm{~nm}}{\text { Abs of blank } 516 \mathrm{~nm}}
\end{aligned}
$$

\section{Results and Discussion}

\section{Isothiocyanates of Capparis cartilaginea}

The GC spectrum of the obtained glucosinolate aglucones of $C$. cartilaginea revealed the presence of four different compounds; (1), (2), (3) and (4) with the following different percentages $(65.03 \%), \quad(29.86 \%)$, $(0.066 \%)$ and $(0.914 \%)$, respectively.

\section{Identification of Compound (1)}

The EI-mass spectrum of compound (1) showed a molecular ion peak at $m / z \quad 115\left[\mathrm{M}^{+}, 11 \%\right]$ where other fragments at $m / z 101\left[\mathrm{M}^{+}-\mathrm{CH}_{2}, 27 \%\right], 73\left[\mathrm{M}^{+}\right.$ $\left.-\left(\mathrm{CH}_{2}\right)_{3}, 68 \%\right]$ and $58\left[\mathrm{M}^{+}-\mathrm{CH}_{3}\left(\mathrm{CH}_{2}\right)_{3}, 32.7 \%\right]$ were found to be the same as that of molecular formula $\mathrm{C}_{5} \mathrm{H}_{9} \mathrm{NS}$. The fragmentation pattern of compound (1) was found to be identical to that of butyl isothiocyanate $\left[\mathrm{CH}_{3}\left(\mathrm{CH}_{2}\right)_{3} \mathrm{~N}=\mathrm{C}=\mathrm{S}\right](7)$.

\section{Identification of Compound (2)}

The EI-mass spectrum of compound (2) showed a molecular ion peak at $m / z 221\left[\mathrm{M}^{+}, 4.5 \%\right]$ which corresponds to the molecular formula $\mathrm{C}_{8} \mathrm{H}_{15} \mathrm{NO}_{2} \mathrm{~S}_{2}$. Other fragments at $m / z 220\left[\mathrm{M}^{+}-1, \mathrm{CH}_{2}, 32.7 \%\right]$, $206\left[\mathrm{M}^{+}-\mathrm{CH}_{3}, 14.5 \%\right], 205\left[\mathrm{M}^{+}-\mathrm{CH}_{4}, 100 \%\right], 142$ $\left[\mathrm{M}^{+}-\mathrm{CH}_{3} \mathrm{SO}, 3 \%\right]$ and 57 [NSC $\left.-1,15.5 \%\right]$ were detected. Thus, compound (2) can be identified as 6methylsulfonylhexyl isothiocyanate $\left[\mathrm{CH}_{3} \mathrm{SO}_{2}\left(\mathrm{CH}_{2}\right)_{6}-\right.$ $\mathrm{N}=\mathrm{C}=\mathrm{S}]$ (Khaled, 2002).

\section{Identification of Compound (3)}

The EI-mass spectrum of compound (3) showed a molecular ion peak at $m / z 235\left[\mathrm{M}^{+}, 3.5 \%\right]$ which corresponds to the molecular formula $\mathrm{C}_{9} \mathrm{H}_{17} \mathrm{NO}_{2} \mathrm{~S}_{2}$ in addition to other fragments at $m / z 220\left[\mathrm{M}^{+}-\mathrm{CH}_{2}\right.$, $5.5 \%], 205\left[\mathrm{M}^{+}-\mathrm{CH}_{3} \mathrm{CH}_{2}, 20 \%\right], 92\left[\mathrm{M}^{+}-\left(\mathrm{CH}_{2}\right)_{6} \mathrm{NCS}\right.$, $22.7 \%]$ and $58\left[\mathrm{M}^{+}-\mathrm{CH}_{3} \mathrm{SO}_{2}\left(\mathrm{CH}_{2}\right)_{7}, 36.4 \%\right]$. From this fragmentation pattern compound (3) could be identified as 7-methylsulfonylheptyl isothiocyanate $\left[\mathrm{CH}_{3} \mathrm{SO}_{2}\left(\mathrm{CH}_{2}\right)_{7}-\mathrm{N}=\mathrm{C}=\mathrm{S}\right](7)$.

\section{Identification of Compound (4)}

The EI-mass spectrum of compound (4) showed a molecular ion peak at $m / z \quad 281 \quad\left[\mathrm{M}^{+}, 10.9 \%\right]$ which corresponds to the molecular formula $\mathrm{C}_{13} \mathrm{H}_{15} \mathrm{NO}_{2} \mathrm{~S}_{2}$ in addition to other fragments at $\mathrm{m} / \mathrm{z} 223$ $\left[\mathrm{M}^{+}-\mathrm{NCS}, 3.6 \%\right], 207\left[\mathrm{M}^{+}-\mathrm{CH}_{3} \mathrm{NCS}-15.4 \%\right], 167$ $\left[\mathrm{M}^{+}-\mathrm{CH}=\mathrm{CH}-\mathrm{CH}_{2}+\mathrm{CH}_{2} \mathrm{NCS}, 27.3 \%\right], 149\left[\mathrm{M}^{+}-\right.$ $\left.\mathrm{SO}_{2} \mathrm{CH}_{-}=\mathrm{CH}-\left(\mathrm{CH}_{2}\right)_{3}, 100 \%\right]$ and $91 \quad\left[\mathrm{M}^{+}{ }_{-} \mathrm{SO}_{2}\right.$ $\mathrm{CH}=\mathrm{CH}-\left(\mathrm{CH}_{2}\right)_{3} \mathrm{NCS}, 70 \%$ ]. From these data, compound (4) could be identified as 5-bezylsulfonyl-4bentenyl isothiocyanate (Tait et al., 1962).

\section{Isothiocyanates of Capparis deserti}

The GC spectrum of the obtained glucosinolate aglucones of $C$. deserti revealed the presence of four different compounds, two of them were identified as compounds (1) and (2) with different percentages $(68.67 \%)$ and $(20.18 \%)$; respectively. The other two compounds (5) $(0.105 \%)$ and $(6)(0.123 \%)$ were identified as follows.

\section{Identification of Compound (5)}

The EI-mass spectrum of compound (5) showed a molecular ion peak at $m / z \quad 147 \quad\left[\mathrm{M}^{+} 4.5 \%\right]$ which corresponds to the molecular formula $\mathrm{C}_{5} \mathrm{H}_{9} \mathrm{NS}_{2}$ in addition to other fragments at $m / z 101\left[\mathrm{M}^{+}{ }_{-} \mathrm{CH}_{3} \mathrm{~S}\right.$, $21 \%], 91\left[\mathrm{M}^{+}-\mathrm{NCS}, 36.4 \%\right]$ and $73\left[\mathrm{M}^{+}-\mathrm{CH}_{3} \mathrm{~S}\right.$ $\left(\mathrm{CH}_{2}\right)_{2}-1,100 \%$ ]. So, compound (5) could be identified as 7-methylthiopropyl-isothiocyanate $\left[\begin{array}{lll}\mathrm{CH}_{3} \mathrm{~S} & \left(\mathrm{CH}_{2}\right)_{3}-\end{array}\right.$ NCS] (7).

\section{Identification of Compound (6)}

The EI-mass spectrum of compound (6) showed a molecular ion peak at $m / z=297\left[\mathrm{M}^{+}, 4.5 \%\right]$ and $\mathrm{M}^{+}-1$ at $m / z=296 \quad(9 \%)$ that corresponds to the molecular formula $\mathrm{C}_{16} \mathrm{H}_{27} \mathrm{NS}_{2}$ in addition to other fragments at $m / z=264 \quad\left[\mathrm{M}^{+}-\mathrm{SH}, \quad 22.7 \%\right]$ and $101(22.7 \%)$ due to the presence of $\left[\mathrm{CH}_{2}-\mathrm{CH}_{2}-\mathrm{CH}_{2}-\right.$ $\mathrm{CH}_{2}-\mathrm{CH}_{2}-\mathrm{N}=\mathrm{C}=\mathrm{S}$ ] which cyclized to the stable form (Fig. 1). Also, a fragment at $m / z 55(100 \%)$ was due to the presence of $\left[\mathrm{CH}_{3}-\mathrm{CH}=\mathrm{CH}-\mathrm{CH}_{2}\right]$. Compound (6) was identified as 11-(2-butenyl thio) 6-undecenyl isothiocyanate (7). This is the first report of isolation and identification of butyl isothiocyanate; 6-methylsulfonylhexyl isothiocyanate; 3-methylthiopropyl-isothiocyanate 


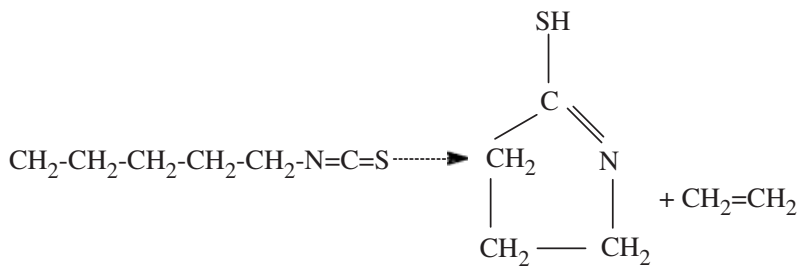

Figure 1. EI mass spectrum of compound (6).

Table 1. UV Spectral data $(\mathrm{nm})$ of the isolated rutin

\begin{tabular}{lllllll}
\hline $\begin{array}{l}\text { Additios } \\
\text { to } \mathrm{MeOH}\end{array}$ & None & $\mathrm{NaOMe}$ & $\mathrm{AlCl}_{3}$ & $\mathrm{AlCl}_{3}+\mathrm{HCl}$ & $\mathrm{NaOAc}$ & $\begin{array}{l}\mathrm{NaOAc} / \\
\mathrm{H}_{3} \mathrm{BO}_{3}\end{array}$ \\
\hline Rutin & 250 & 275 & 273 & 276 & 269 & 265 \\
& $268 \mathrm{sh}$ & 332 & $306 \mathrm{sh}$ & 298 & $328 \mathrm{sh}$ & 301 \\
& $296 \mathrm{sh}$ & 406 & 430 & $357 \mathrm{sh}$ & 387 & 384 \\
& 354 & & & 404 & & \\
\hline
\end{tabular}

and 11-(2-butenyl thio) 6-undecenyl isothiocyanate from C. deserti.

\section{Identification of the Main Flavonoidal Compound (rutin)}

Preparative PC followed by Sephadex $\mathrm{LH}_{20}$ column gave a single flavonoidal compound corresponding to that of rutin (UV data: Table 1). Acid hydrolysis gave quercetin which was identified by TLC, PC, UV and MS $\left(\mathrm{M}^{+} 302\right.$, $\left(\begin{array}{lll}\mathrm{C}_{15} & \mathrm{H}_{10} & \left.\mathrm{O}_{7}\right)\end{array}\right)$ and fragments at $\mathrm{m} / \mathrm{e} 274,152,153,134$. Glucose and rhamnose were confirmed by PC [Whatman No. 1, ethyl acetate: pyridine: water (12: 5: 4)]

\section{Quantitative Determination of Rutin by TLC-Densitometer}

The standard rutin has been subjected to TLCDensitometeric evaluation under suitable conditions. This technique proved that, it is suitable for the detection of rutin under the selected conditions. Standard curve of authentic rutin $\left(R_{f}=0.56\right)$ were made with serial concentration starting from $200 \mathrm{nl}$ to $1200 \mathrm{nl}$ on the TLC stationary layer. The prepared samples under investigation were analyzed under the same conditions as the standard rutin. The rutin concentrations, in the different prepared samples, were calculated automatically using CATS 4 Software.

The results revealed that the highest percent of rutin was found in butanol fraction of $C$. deserti $(12.5 \%)$ followed by ethylacetate fraction of the same species $(9.84 \%)$. On the other hand, the rutin in the butanol fraction of C. cartilaginea was found only in $5.6 \%$, while in the ethylacetate fraction, rutin could not be detected in the tested concentrations up to $12000 \mathrm{nl}$ (Table 2). The radical scavenging effect of the tested extracts on DPPH free radical was performed (Table 3). The butanol fractions of both $C$. deserti and C. cartilaginea had the
Table 2. Rutin determination in Capparis Species

\begin{tabular}{lll}
\hline Capparis species & Fraction & Rutin\% \\
\hline C. cartilaginea & Butanol & 5.6 \\
& ethylacetate & not detected \\
C. deserti & Butanol & 12.5 \\
& ethylacetate & 9.84 \\
\hline
\end{tabular}

Table 3. Antioxidant activity of different plant extracts

\begin{tabular}{lcl}
\hline Capparis species & $\begin{array}{l}\text { Capparis Cartilaginea } \\
\% \text { antioxidant activity }\end{array}$ & $\begin{array}{l}\text { Capparis deserti } \\
\% \text { antioxidant activity }\end{array}$ \\
\hline Extract & & \\
Tolorox & 94.96 & 94.96 \\
$\mathrm{MCM}$ & 0 & 0.6 \\
$80 \%$ aq. EtOH & 10.87 & 6.95 \\
Water & 0 & 0 \\
$\mathrm{CHCl}_{3}$ & 66.75 & 65.73 \\
EtOAc & 0.1 & 23.38 \\
BuOH & 77.24 & 72.94 \\
Glucosinolates & 0 & 0 \\
Pet. Ether & 0 & 0 \\
\hline
\end{tabular}

highest antioxidant activity followed by the $\mathrm{CHCl}_{3}$ extracts. Also, EtOAc of $C$. deserti showed mild antioxidant properties. MCM extract, total glucosinolates, EtOAc and pet. Ether extracts of both species showed no antioxidant activity. The results are expressed as radical scavenging activity (\%RSA) as shown in the table.

\section{References}

1. Boulos L. Flora of Egypt, Vol. 1, 1st edn. Cairo, Egypt: Al Hadara Publishing, 1999, 170.

2. Täckholm V. Student's Flora of Egypt, 2nd edn. Beirut: Cairo University Cooperative Printing Company, 1974, 162.

3. Gunther R. The Greek Herbal of Dioscorides, New York: Hafner Publishing Co, 1959, 215.

4. Shahina AG. Capparaceae. In: Boca Raton (ed). USA: CRC Press, Inc., 1994, 73.

5. Batanouny KH. (with contribution of: Aboutabl E, Shabana M, Soliman F.) Wild Medicinal Plants in Egypt. Switzerland: Academy of Scientific Research and Technology, Egypt, International Union for Conservation (IUCN), 1999, 130-1.

6. Sharaf M, El-Ansari MA, Saleh NA. Flavonoids of four Cleom and three Capparis species. Biochem Syst Ecol 1997;25:161-166.

7. Kjaer A, Ohashi M, Wilson JM, Djerassi C. Mass spectra of isothiocyanates. Acta Chem Scand 1963;17:2143-54.

8. Mabry TJ, Markham KR. The Flavonoids. In: Harborn JB, Mabry TJ, Mabry M (eds). London: Chapman and Hall, 1975.

9. Mabry TJ, Markham KR, Thomas MB. The Systematic Identification of Flavonoids. Springer Verlag, Berlin, 1970.

10. Ahmed ZF, Rizk AM, Seif El-Nasr MM. Glucosinolates of Egyptian Capparis Species. Phytochemistry 1972;11:251-6.

11. Tait JMS, Shannon TW, Harrison AG. J. Am. Soc. 1962;84:4.

12. Khaled AA. Chemical Studies on Certain Plants of Crucifera. Ph.D. Thesis 2002, Faculty of Science, Cairo University. 


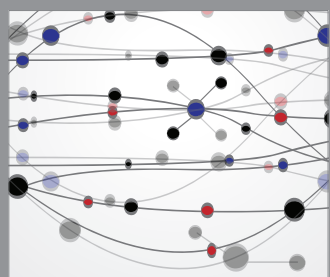

The Scientific World Journal
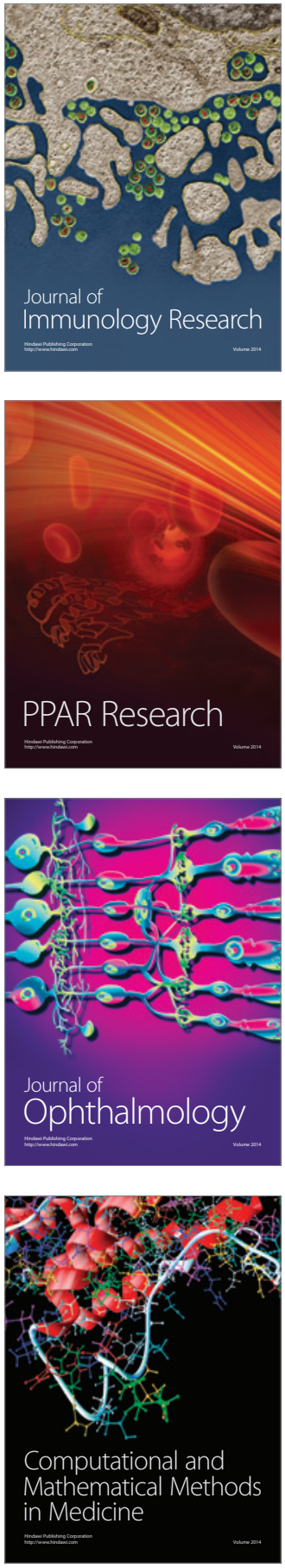

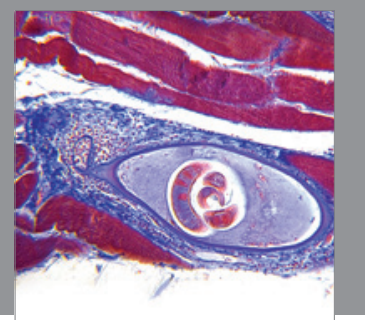

Gastroenterology

Research and Practice
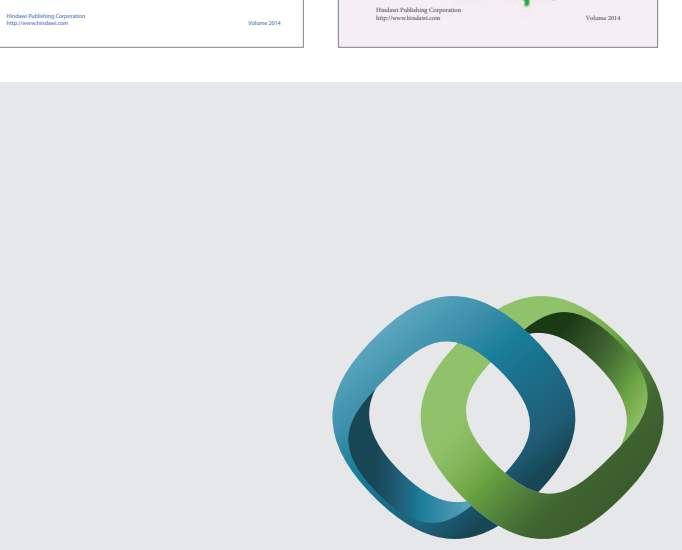

\section{Hindawi}

Submit your manuscripts at

http://www.hindawi.com
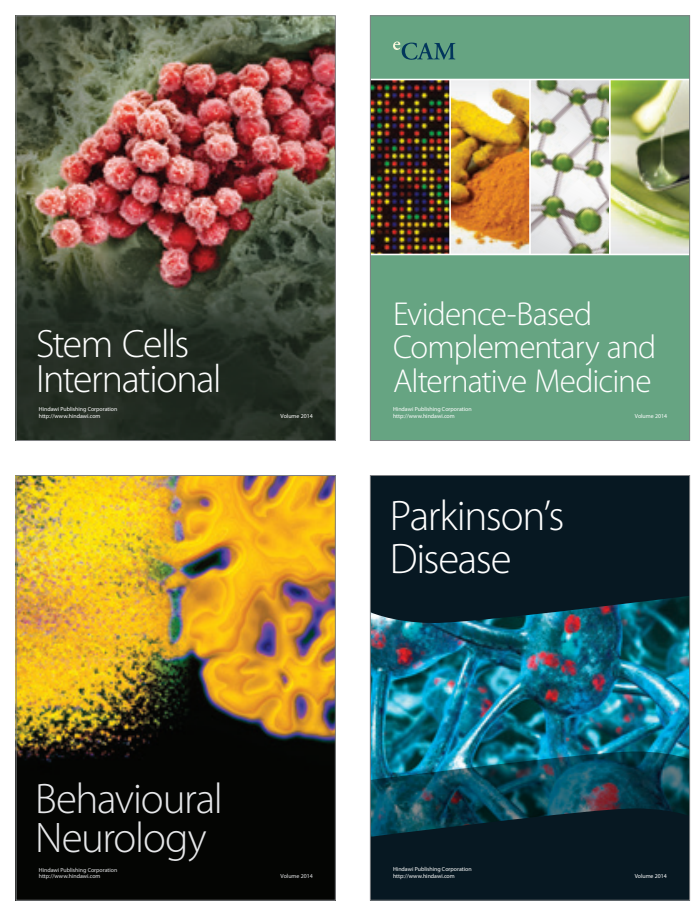

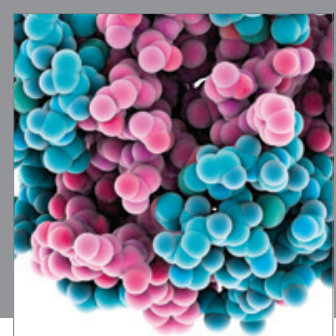

Journal of
Diabetes Research

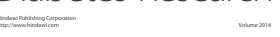

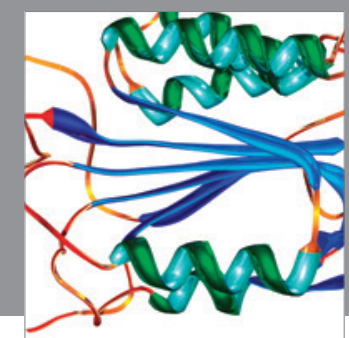

Disease Markers
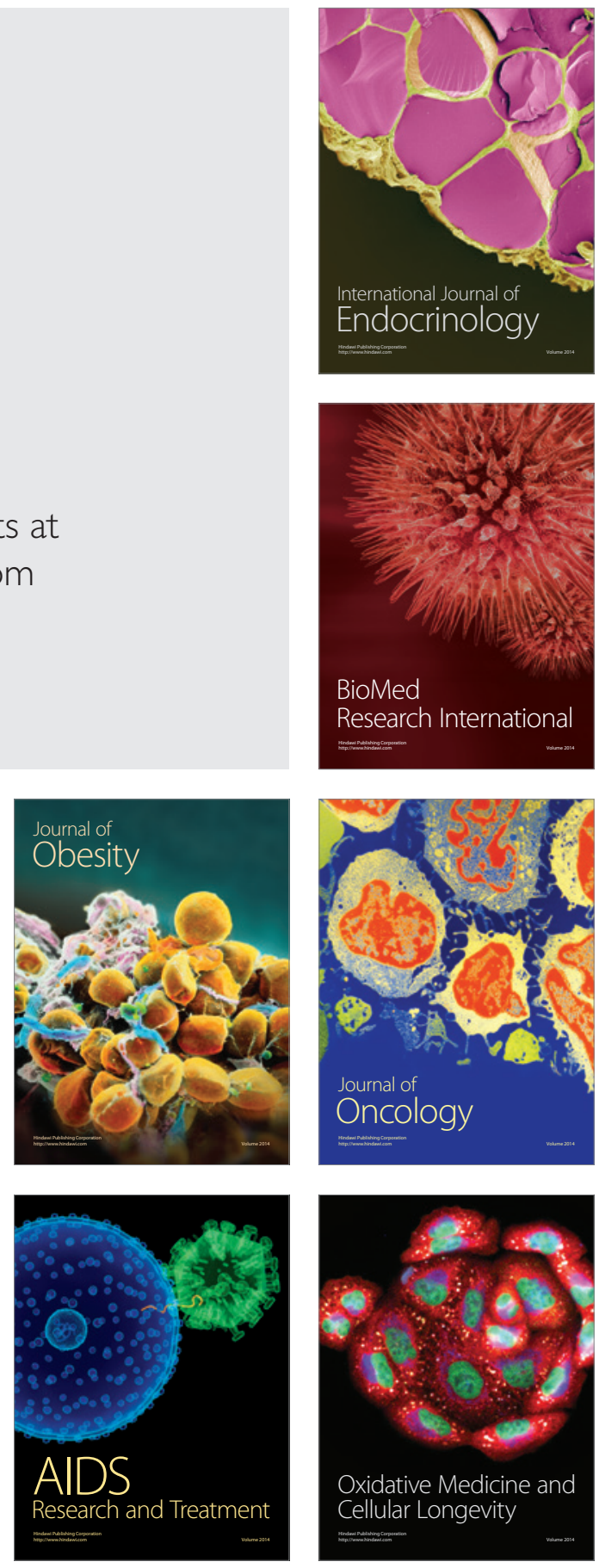